\title{
How do former smokers perceive information about nicotine products? Evidence from Sweden
}

\section{Tove Sohlberg and Patrik Karlsson}

Tove Sohlberg is based at the Department of Sociology, Stockholm University, Stockholm, Sweden.

Patrik Karlsson is based at the Department of Social Work, Stockholm University, Stockholm, Sweden.
Received 17 July 2020 Revised 6 October 2020 29 January 2021

31 March 2021

Accepted 3 April 2021

(C) Tove Sohlberg and Patrik Karlsson. Published by Emerald Publishing Limited. This article is published under the Creative Commons Attribution (CC BY 4.0) licence. Anyone may reproduce, distribute, translate and create derivative works of this article (for both commercial and non-commercial purposes), subject to full attribution to the original publication and authors. The full terms of this licence may be seen at http:// creativecommons.org/licences/ by/4.0/legalcode

This work was supported by Forskningsrådet om Hälsa, Arbetsliv och Välfärd: [FORTE] (Grant/Award number:201600917).

\begin{abstract}
Purpose - Health promotion strategies often attempt to change people's behavior through targeting their risk perceptions. These perceptions may, however, be moderated by other factors. This study therefore aimed at investigating the trustworthiness and consistency of risk information, as well as respondent perceptions of the adequacy of amount received among a representative sample of former smokers, and how this information is related to gender, age, education level and whether using nicotine or not.

Design/methodology/approach - The respondents are part of a seven-year follow-up of former smokers in Sweden. Initially, 1400 respondents were contacted, whereof 705 (response rate 50\%) answered a Web-survey. The majority (85\%) was still nicotine-free but some made use of nicotine in different forms. The data analysis includes descriptive statistics and logistic regressions.

Findings - Most respondents trusted risk information whether offered by the public authorities or came from other sources such as media, and generally perceived that there was an adequate amount. However, there were some differences between the products, where quite a few distrusted information on Nicotine Replacement Therapies (NRTs) and some perceived the information on snus and NRTs as contradictory and too little.

Originality/value - Knowledge about how former smokers perceive information regarding negative aspects of cigarette use may facilitate more effective risk communication with current smokers, and it may also be important for communicating information about other nicotine products to those who are trying to or who already have quit smoking.
\end{abstract}

Keywords Risk information, Perception, Attitudes, Former smokers, Snus, NRT

Paper type Research paper

\section{Introduction}

There is a downward global trend in smoking, but even so, tobacco causes the premature death of more than eight million people each year, whereof one million due to second hand smoke exposure (WHO, 2020). There are a number of negative medical effects of smoking including, for example, lung cancer and cardiovascular diseases. As such, reducing smoking is a top public health priority in a number of countries.

In Sweden, smoking has been declining since the 1980s and the total share of daily smokers in the population is estimated to be only about $10 \%$, with an additional $6 \%$ only smoking occasionally (Statistics Sweden, 2020). Sweden has thereby the lowest prevalence rate of daily tobacco smoking in the entire European Union (EU) (Eurostat, 2019) and a low tobacco related ill-health and mortality. Even so, about 12000 persons in Sweden die each year and almost 100000 are annually afflicted by smoking-related diseases (Swedish National Board of Health and Welfare, 2014). In order to mitigate this public health issue, a number of tobacco control policies have been introduced in the country following the WHO Framework Convention on Tobacco Control (FCTC) and the EU Tobacco Products 
Directive. For example, a strengthening of the smoking ban has recently been put in to place (Law on Tobacco and Similar Products 2018:2088) both to support those who want to quit smoking and to reduce harm to others.

Other products considered to decrease harm both to others and to users is the Swedish snus (moisturized tobacco to place under the lip) along with Nicotine Replacement Therapies (NRTs). The FCTC states that harm reduction is one of the strategies of tobacco control (FCTC 2005, Article 1d) and, as concluded in a recent review by Clarke et al. (2019), snus is a less harmful alternative to smoking.

Today, snus is used on a daily basis by almost $13 \%$ of the Swedish population (+16 years) (Statistics Sweden, 2020); it can be bought in almost every retail store and use is not subject to any restrictions, besides an age limit for purchase of 18 years. NRTs, such as nicotine chewing gum and plasters, are considered medical aids for smoking cessation, sold at pharmacies and over the counter in retail stores to individuals over 18 years.

Drawing upon a follow-up study of a sample of former smokers, this study explores how risk information related to smoking, snus and NRTs are perceived and whether such perceptions are related to gender, age, educational level and whether or not using nicotine. We address three different outcomes related to how the risk information is perceived: trust in information from public authorities, consistency of information received and perception of adequacy in the amount of information given.

Studies on how former smokers perceive information pertaining to cigarettes may facilitate more effective risk communication with people still smoking and may also be crucial for communicating useful information about other nicotine products to those who are trying to or who already have quit smoking. While a prior study has explored how information on different substances is perceived among the general population in Sweden (Ekendahl and Karlsson, 2015), we lack detailed knowledge about how those issues are perceived among the former smoking group and factors that could potentially correlate with such perceptions in this group.

As Sweden has a long tradition of providing information to the assumed rational individual, the level of trust in public authorities is in general high (not least noted by the surrounding world in these times of corona virus and the "Swedish strategy"). However, communication is a two-way process. Without listening to people, it is impossible to understand what they know, and therefore impossible to provide them with relevant information. We therefore consider this study to make an important contribution to the existing knowledge.

\section{Risk and risk information}

Risk can be understood as the probability that an event will occur and the magnitude of its consequences (Rayner and Cantor, 1987). Perception of risk is the subjective assessment of the probability, as well as the consequences of a negative outcome (Sjöberg et al., 2004), and is often thought to influence the actions that people make (Sheeran et al., 2014). Consequently, health promotion efforts often attempt to change people's behavior through targeting their risk perceptions (see e.g. Kozlowski and Sweanor, 2016).

To make a wise decision, the individual needs knowledge on the pros and cons of different alternatives. This knowledge can stem from public authorities, but also from other sources, e.g. websites, TV, magazines or friends. The risk must be communicated in a trustworthy way (Covello and Sandman, 2001) and designed to bridge the gap between what people know and what they need to know to make well-founded decisions (Fischhoff et al., 1993). Thus, providing information is a central public health strategy. However, risk-perception measures in tobacco research are not consistent and in need of the development and communication of best practices (Kaufman et al., 2020). 
The basic assumption of information provision may be to prevent the taking up of a given behavior, or to facilitate behavioral change among those engaged in the particular behavior. Such communication could be framed as goal framing ("if you smoke [...]/if you don't"), risk information (e.g. "smoking causes [...]/quitting will improve your health") and presenting risk reduction (e.g. "smoking is associated with [...]/snus use is associated with less [...] ") (Haroon Ahmed et al., 2012). The information may sometimes be factual, and sometimes be more fear provoking.

However, as decades of substance-use prevention research among youth have shown, information often fails to affect behavior (Carney et al., 2016).

The amount of information available is sometimes greater than our ability to process it (Johnson, 2014), creating a situation of uncertainty and lack of trust (Benigeri and Pluye, 2003). This so called "information overload" can be avoided, both on an individual and social level, by the use of coping strategies such as filtering or withdrawing (Bawden and Robinson, 2020). Information overload then becomes a hindrance rather than a help (Bawden and Robinson, 2009). Also, as should be quite evident during the current Covid-19 situation, the information provided can be contradictory. Thus, more information does not necessarily make people more confident in how to properly act; it can also increase their uncertainty. However, whether the information is perceived as contradictory or not is highly likely to vary according to the behavior it refers to.

In Sweden, the first inquiry into the growing use of tobacco was conducted as early as 1918. The conclusion was that information was the key to a healthy way of living and up until the 1960s tobacco control was characterized by a consensus driven belief in the power of information. Today, the Government's national Alcohol, Narcotics, Doping, and Tobacco policies consist of a combination of several different measures, whereof information is only one part. Obviously, the country has a long tradition of information as part of tobacco prevention policies, resting on the assumption that individuals will take rational responsibility for their own health. Public health, however, depends on the public's ability to understand the information and then make a choice based on that knowledge. So, what is known?

\section{Known risks with tobacco/nicotine use}

The impacts of one's risky behavior may be either acute or chronic. The latter is when a hazardous process continues over time (Rohrmann and Renn, 2000), as for example smoking.

Smoking undoubtedly leads to premature death and such negative health consequences as lung diseases, different forms of cancer, cardiovascular diseases and type 2 diabetes. This must be considered common knowledge, at least in the West, even though the medical details may be less clear. However, smoking related diseases like these take time to develop (Bolin and Lindgren, 2004) and the consequences may thus be hard to foresee. The risks of smoking are set in the future.

The overall increase in snus use at the expense of cigarette smoking has led to decreasing rates of smoking-related negative health consequences (Sohlberg, 2014) and indeed experts have found a 90-95\% reduction in the mortality risk when using snus instead of smoking cigarettes (Levy et al., 2004; Nutt et al., 2014). Hence, the health risk associated with using snus is minor compared to the risks from smoking (Nutt et al., 2014). The US Food and Drug Administration (FDA) concluded that snus puts people at a lower risk for different diseases in comparison to smoking and then authorized Swedish Match General snus as a modified risk tobacco product (FDA, 2019). Nonetheless, snus is not recommended as a means to becoming smoke-free either by the European Commission (2008) or by national public health advocates such as the Swedish Quit-smoking-line (2019), nor by relevant NGOs such as Psychologists Against Tobacco (2017). However, this stance is not only based on a comparison of the risks of using snus relative to smoking cigarettes; the health risk when using snus overall is also a central concern. Studies have found a slightly increased risk for pancreatic cancer (Luo et al., 
2007) and type 2 diabetes (Carlsson et al., 2017), but no evidence for oral or lung cancer (Luo et al., 2007), colorectal cancer (Nordenvall et al., 2010) or cardiovascular diseases (Hansson, 2009). In spite of the scarce scientific evidence the EU tried to strengthen the risk message on snus cans by changing "can damage" in "This tobacco product can damage your health and is addictive" to simple "damages" (Directive 2014/40/EU). The discrepancy between scientific evidence and the perception of risk is underlined by a recent study from Norway, a country with snus prevalence equal to that of Sweden: the belief in risk with using snus daily was shown to be equivalent to about $80 \%$ of the perceived risks of smoking daily. Hence, the perception of the relative risk between snus and cigarettes does not reflect the medical evidence (Lund and Vedoy, 2019), and this risk continuum has not been communicated to the public.

Similar to the case with snus, most studies focus on long-term NRT use, versus being a smoker, and ill health (see e.g. Shields, 2011), but the use has not been shown to increase the risk, for example, myocardial infarction, stroke, or death (Hubbard et al., 2005). In Sweden, NRTs are considered medical products, with an age limit for purchase of 18 years, and is primarily sold in pharmacies, but also at grocery store checkouts. NRTs are recommended as a means to quit smoking both by the manufacturers (e.g. Nicorette) and by NGOs like Psychologists against Tobacco (http://www.psychologistsagainsttobacco. org/metoder-for-rok-och-snusstopp). The general aim of this study is to investigate how different aspects of risk information are perceived on an individual level by former smokers. More specifically, we explore the following:

- the extent to which risk information provided by the public authorities regarding cigarette smoking, snus use and the use of NRTs is trusted;

- the extent to which risk information regarding these nicotine products provided by other sources is perceived as consistent; and

- whether individuals think they receive an adequate amount of risk information from public authorities regarding these products.

\section{Data and method}

Data. The present study is based on a representative sample of former smokers among the Swedish population. The respondents were originally recruited from the Monitor Project, a running monthly survey directed to a representative sample of 1,500 respondents aged 16-84 years (18 000 per year), conducted at the Centre for Social Research on alcohol and Drugs (SoRAD, now within the Department of Public Health Sciences at Stockholm University) between the years 2000 to 2012. During the period October 2009 to May 2010 a sample of former smokers ( $n=1882)$ was recruited for a study about smoking cessation with a response rate over $89 \%(n=1683)$. These respondents are now part of a seven-year follow-up with the overall aim of revealing factors affecting long-term smoking cessation (smoke-free for at last the latest 12 months) on an individual level. Both studies were approved by the Regional Ethical Review Board in Stockholm (2009/2102-31/5; 2017/561-31/5).

For various reasons (unknown address, moved abroad, deceased) 283 individuals could not be found for the second data collection, so in total 1400 respondents were contacted regarding participation and asked to answer a Web-based survey that ran from August 2017 to February 2018. The survey covered, e.g. the use of snus and other nicotine products, health and lifestyle and, as investigated in this article, the trustworthiness of risk information. The response rate was about 50\% $(n=705)$. A non-response analysis on the follow-up showed no significant differences between participants and non-participants in such sample characteristics as gender, age, education or economic status. In the present study a majority (85\%) is not only smoke-free but nicotine-free. However, some have relapsed and are using nicotine in the form of daily or occasional smoking again. Others used snus or NRTs such as nicotine chewing gum when quitting smoking and are still using. 
Variables. The approach to risk information gained inspiration from a previous study based on a general population sample of Swedish adults (Ekendahl and Karlsson, 2015). This study uses questions similar to that study, although with different substances.

Dependent variables. To examine different aspects of available information on these three substances, the respondents were asked about the following:

- Trust in risk information measured with the question "How much do you trust the information that is conveyed by public authorities regarding risks with use of [...] (cigarettes, snus, NRTs)?", with alternatives ranging from 1 (completely) to 4 (not at all).

- Consistency of risk information was measured with the question; "Daily we get a lot of information from various sources. We talk to friends, read newspapers, watch TV, go online and so forth. Do you think that the information you get from these different sources is contradictory when it comes to risks with use of [...]. (cigarettes, snus, NRTs)?" Here response alternatives ranged from 1 (contradictory) to 4 (noncontradictory).

- Adequacy of amount of risk information was measured with the question "Do you think that you receive too little or too much information from public authorities regarding risks with use of $[\ldots]$ (cigarettes, snus, NRTs)?".

The alternatives ranged from 1 (too little information) to 5 (too much information) and included a neither/nor option.

Independent variables. The background variables were gender, age (present) and highest achieved educational level, with the alternatives "9years or less", "secondary school" or "university". Respondents were also asked to state whether they smoked daily or only occasionally, or used snus or NRTs daily.

Analyses. First, descriptive analyses on background characteristics such as gender, age, educational level and nicotine status were performed. Those who smoked (daily or occasionally) or used snus or NRTs were collapsed into one single category - nicotine users. All others were then categorized as nicotine-free.

Second, as some cells were too small, the outcome variables for trust and contradictory information were dichotomized by collapsing the first and second alternatives into one value and the third and fourth alternatives into another value (percentage distribution shown in Tables 2 and 4, respectively). The question about amount of information was recoded into three categories (see percentage distribution in Table 6).

Third, multiple logistic regression analyses were performed in order to predict the odds for perceiving the risk information as trustworthy, contradictory or as not being enough. Here, the categories of receiving an adequate amount and too much information were collapsed into one single category. Covariates included were gender, age (present), educational level (highest achieved) and nicotine status (using or not).

Due to some item non-response $n$ does not add up to 705 in the analysis.

\section{Results}

Background characteristics are shown in Table 1.

The sample is overall quite well educated and comprises more women than men. The mean age is 66 years. A total of 109 respondents still used nicotine, but only a few respondents had relapsed and smoked daily $(n=8)$, while others smoked only occasionally $(n=34)$ or used NRTs $(n=8)$. Snus use $(n=59)$ is shown to be of most common usage.

As shown in Table 2, a vast majority trusted information from the public authorities. Risk information on cigarettes was most trustworthy with slightly less trusting the information on snus and even less the information on NRTs. 
Gender

Female

Male

394

308

705

Educational level

9 years or less

153

243

306

109

\begin{tabular}{llcr} 
Table 2 & $\begin{array}{l}\text { Trust in risk information provided by public authorities regarding cigarettes, snus } \\
\text { and NRTs.\% }\end{array}$ & Cigarettes & Snus \\
& 94.0 & 86.1 & 76.8 \\
\hline Complete or quite a lot & 6.0 & 13.9 & 23.2 \\
Quite little or not at all & 681 & 646 & 650
\end{tabular}

The multiple logistic regressions in Table 3 show only one statistically significant association, namely an increased distrust in the information on NRTs among those whose highest education level is secondary school. However, even though not significant, it is of interest that the odds ratio indicates that women seem to distrust the information on snus and that a low level of education is associated with a higher trust. In Sweden, snus is mostly used by men and workers.

Table 4 shows the share perceiving risk information from sources like friends or media as consistent. Over $80 \%$ found the information non-contradictory regarding cigarettes, but when it comes to snus and NRTs only about two-thirds found this information consistent.

Table 3 Lack of trust in risk information provided by the public authorities regarding cigarettes, snus and NRTs. Logistic regression, odds ratios. $(95 \% \mathrm{Cl})$

\begin{tabular}{lccc} 
& Cigarettes & Snus & NRT \\
\hline Gender & & 1 & 1 \\
Men & 1 & 1.35 & 0.97 \\
Women & 0.65 & $0.86-2.14)$ & $(0.66-1.41)$ \\
& $(0.33-1.25)$ & 0.99 & 1.02 \\
Age & 1.01 & $(0.97-1.00)$ & $(0.99-1.03)$ \\
& $(0.98-1.04)$ & & 1 \\
Education & & 1 & 1.54 \\
University & 1 & 1.19 & $(1.02-2.34)$ \\
Secondary school & 1.96 & $0.71-1.96)$ & 1.05 \\
& $(0.93-4.1)$ & 0.92 & $(0.64-1.74)$ \\
9years or less & 1.51 & $(0-49-1.75)$ & 1 \\
& $(0.63-3.59)$ & & 1.11 \\
Nicotine status & & 1 & $(0.63-1.89)$ \\
Non-user & 1 & 0.64 &
\end{tabular}

Notes: ${ }^{*} p<0.05 ; \mathrm{Cl}=$ confidence interval 
Table 4 Perceived consistency of risk information from other sources (newspapers, TV internet etc.) regarding cigarettes, snus and NRTs. \%

\begin{tabular}{lccc} 
& Cigarettes & Snus & NRTs \\
\hline Contradictory & 18.3 & 32.4 & 32.2 \\
Non-contradictory & 81.7 & 67.6 & 67.8 \\
N & 639 & 627 & 609
\end{tabular}

As shown in Table 5, neither gender, age, education nor nicotine status was significantly related to perceiving the information as inconsistent for snus or NRTs. Lower levels of education were significantly associated, as regards cigarettes, with less reported inconsistency. Stated differently, individuals with a university degree had a 2.56 times higher odds than those with secondary school (1/0.39) of perceiving the information pertaining to cigarettes as inconsistent, and a 1.89 higher odds than those with 9 years of schooling or less (1/0.53).

Table 6 shows whether the respondents perceived that the received amount of information from public authorities was too little, adequate or too much. Overall, most reported that they found the amount to be adequate, but there are some differences between the substances; slightly more respondents perceived the amount of information on snus, as well as NRTs, to be too little.

Table 5 Perceived inconsistency of risk information from different sources regarding cigarettes, snus and NRTs. Logistic regression, odds ratios. $(95 \% \mathrm{Cl})$

\begin{tabular}{lccc} 
& Cigarettes & Snus & NRT \\
\hline Gender & & & 1 \\
Men & 1 & 1 & 1.12 \\
Women & 1.44 & 1.01 & $(0.84-1.70)$ \\
Age & $0.95-2.20)$ & $(0.72-1.43)$ & 1.00 \\
& 1.00 & 1.01 & $(0.99-1.02)$ \\
Education & $(0.98-1.02)$ & $(1.0-1.03)$ & 1 \\
University & & & 0.92 \\
Secondary school & 1 & 1 & $(0.63-1.35)$ \\
& $0.39^{* * *}$ & 0.98 & 1.12 \\
9years or less & $(0.24-0.64)$ & $(0.67-1.44)$ & $(0.70-1.81)$ \\
& $0.35^{* * *}$ & 1.06 & 1 \\
Nicotine status & $(0.20-0.60)$ & $(0.67-1.68)$ & 0.92 \\
Non-user & & 1 & $(0.56-1.52)$ \\
User & 1 & 0.91 & \\
& $(0.26-1.10)$ & $(0.55-1.50)$ &
\end{tabular}

Table 6 Attitude toward amount of risk information from public authorities regarding cigarettes, snus and NRTs. \%

\begin{tabular}{lccc} 
& Cigarettes & Snus & NRTs \\
\hline Too little information & 32.3 & 38.8 & 40.2 \\
Adequate amount of information & 59.9 & 55.1 & 52.9 \\
Too much information & 7.8 & 6.2 & 7.0 \\
N & 679 & 650 & 647
\end{tabular}


Table 7 shows that education and nicotine status were unrelated to the perceived amount of information regarding the substances, but that there was a significant gender and age gradient across all three nicotine products. The odds for perceiving information received as too little are higher for women than for men and with increasing age the odds for reporting too little information increased. The magnitude of the associations for gender and age was similar across nicotine products. However, regarding NRTs, a low level of education was associated with perceiving the information as too little.

\section{Discussion}

This study aimed at investigating the trustworthiness and consistency of risk information concerning nicotine usage and the adequacy of the amount of information offered as perceived by a representative sample of former smokers. Overall, the results regarding cigarettes and snus are in line with findings from Ekendahl and Karlsson's (2015) study based on a random sample of Swedish adults. One key result is that a majority of the respondents trusted information given by public authorities, even though slight differences between the products emerged. The logistic regressions, however, only showed one significant association, namely that those with a lower level of education distrusted the information on NRTs.

Another important finding is that risk information provided by other sources was perceived as non-contradictory by a majority. However, the difference between products that we saw regarding information from the public authorities is more scattered in this case. About onethird actually perceived information on snus and NRTs as contradictory. In the logistic regressions only education had a significant relationship with the outcome, where those with less than university education perceived the information as less contradictory.

A third result was that while most of the respondents perceived that they had received an adequate amount of risk information, quite a few stated that there was too little information, especially regarding snus and NRTs. The logistic regressions showed that women perceived that they had received too little information on all three products, and this attitude also increased with age. Also, those with the lowest level of education reported too little information on NRTs.

Overall, the logistic regressions show education to be most important for attitudes toward risk information. Individuals with a low level of education were significantly more prone to perceive information regarding all three substances as less contradictory. Low educated

\section{Table 7 Received too little risk information from public authorities regarding cigarettes,} snus and NRTs. Logistic regression, odds ratio. $(95 \% \mathrm{Cl})$

\begin{tabular}{lccc} 
& Cigarettes & Snus & NRT \\
\hline Gender & & 1 & \\
Men & 1 & $1 \ldots 5^{* * * *}$ & 1 \\
Women & $1.94^{* * \ldots *}$ & $1.91^{* *}$ \\
& $(1.38-2.73)$ & $(1.32-2.57)$ & $(1.37-2.67)$ \\
Age & $1.02^{* *}$ & $1.02^{* *}$ & $1.02^{* *}$ \\
& $(1.01-1.04)$ & $(1.01-1.04)$ & $(1.01-1.04)$ \\
Education & 1 & 1 & 1 \\
University & 0.90 & 1.14 & 1.23 \\
Secondary school & $(0.62-1.32)$ & $(0.79-1.66)$ & $(0.85-1.78)$ \\
& 0.86 & 1.14 & 1.60 \\
9years or less & $(0.56-1.34)$ & $(0.74-1.77)$ & $(1.03-2.51)$ \\
Nicotine status & 1 & 1 & 1 \\
Non-user & 0.86 & 0.87 & 0.81 \\
User & $(0.53-1.39)$ & $(0.54-1.39)$ & $(0.50-1.31)$ \\
& &
\end{tabular}


individuals may be less inclined to question information, especially from authorities. However, those with a low level of education distrusted the information regarding NRTs and sensed that they had perceived to little information. As information from authorities is perceived as non-contradictory, and most information on NRTs comes from manufacturers, it may not be too surprising.

There was little evidence of gender differences except for the amount of information received. Women generally lacked risk information on all three substances and this lack of risk information was also associated with an increase in age. This sample consists of former smokers, with a quite a high middle age, and because women often have a harder time than men to quit smoking (Sohlberg, 2014), this attitude might reflect an opinion that risks should be communicated in a larger amount to the population, both to deter smoking initiation and to facilitate a more healthy lifestyle.

The participants in this study were asked how they perceived information pertaining to three nicotine products. The scientific certainty pertaining to risks associated with these is highly variable. The research on smoking is broad, ambitious and in agreement, and the Swedish public health authorities base their information on relevant (often evidence-based) scientific studies. Also, general practitioners in Swedish health care seems to be knowledgeable about the risks with cigarette use, a finding that also holds true among their English counterparts (Patwardhan and Murphy, 2013).

Hence, the risk information pertaining to cigarette use is backed up by both international and national studies on mortality and ill-health, and is established via tobacco control policies and disseminated in the society mostly via public health advocates, medical doctors and scientists, i.e. by actors with high credibility, and in a trustworthy way. This is probably why most respondents experience high trust and consistency regarding information on cigarette use. Also, these former smokers have experiences of smoking connected to emotions and perceived severity of effects, and this is found to be related to heightening risk perceptions (Sheeran et al., 2014).

When it comes to snus, the scientific research on risk is scarce, something that does not hinder the EU, for example, from arguing that the product causes damage to the health (Directive 2014/40/EU), although health risks associated with snus use are significantly lower than those associated with cigarette smoking (Clarke et al., 2019). Moreover, it has been estimated that a switch from cigarettes to snus reduces the mortality risk by about 90\% (Levy et al., 2004).

But risk/harm reduction is a sensitive topic. Based on public health considerations snus is prohibited in the EU, but Sweden is exempted from this ban. The official standpoint from the Conservative government (2006-2014) was that snus should be considered as a less harmful alternative to cigarettes and a potential way to quit smoking. This was questioned by both the EU and by national NGOs. The European Commission (2008) claims that because there are no controlled scientific studies, snus as a smoking cessation aid is not an evidence-based method.

Following Haroon Ahmed et al (2012), communication is in general framed as risk information on both pros and cons with quitting or continuing with a certain substance use. Presenting risk reduction is, however, a neglected area of Swedish tobacco control, and it is fair to say that omitting such health-relevant information reduces the possibility of making informed personal choices (Kozlowski and Sweanor, 2016).

Moreover, as stated by Lund and Vedoy (2019), there are a number of incorrect beliefs regarding the risks associated with snus use - underlining the importance of accurate information on differential harms. As the medical evidence on harm caused by snus use is scarce and the information provided does not include the risk reduction aspect, it is not too surprising that the participants perceived it to be too little and somewhat contradictory.

PAGE $320 \mid$ DRUGS AND ALCOHOL TODAY $\mid$ VOL. 21 NO. 42021 
NRTs are sold as medical aids to becoming smoke-free and are to a great deal promoted by the manufacturers themselves via media and TV commercials. So, even if sold at pharmacies, information to the public on these nicotine products could easily be perceived as less trustworthy, more contradictory and too little of scientific-based information than the information regarding cigarettes.

Worth noticing is the difference between snus and NRT regarding marketing; while snus is promoted only via so-called point-of-sale, near to the check-out counter, NRT is promoted by public health care and has no marketing restrictions.

\section{Limitations and strengths}

These results must be considered in light of certain limitations. First, the monitor data is thought to constitute a representative sample of the Swedish population. However, the research company merely followed the requirement to deliver data from 1,500 respondents each month so that those who could not be reached were replaced with others. The missing data increased over time and were about 60\% in 2010 (Ramstedt et al., 2013). This circumstance raises the question of representativity. However, a previous study found no difference between non-respondents and a concurrent sample of respondents in tobacco use (Wennberg et al., 2011).

Moreover, the response to questions of how the respondents perceived given risk information is subjective and could eventually be difficult to interpret, but the sample is overall well educated and the internal missing values are few.

The present data on former smokers with its high response rate in 2010 (over 89\%) is rather unique in a Swedish context. Even more so is this follow-up where almost half participated as long as 7 years later. This indicates not only a commitment to contribute to tobacco research, but an interest in the topic itself. It is therefore concluded that their answers are indeed thoughtful.

\section{Conclusion}

Former smokers have substance specific experience, having all smoked cigarettes, though some have quit smoking by using snus or NRTs. This study suggests that information on risks of cigarette use is highly trustworthy, perhaps due to (now) common knowledge about such risks based on scientific research. Information on snus, however, is quite contradictory depending on whether it is seen as harm reduction or as another harmful tobacco product. NRTs are recommended within the medical sphere as a way of becoming smoke-free, but information to the public is mostly through the specific manufacturers' advertising.

Information should therefore deal not only with risks, but also with risk reduction, be based on scientific research and communicated by, e.g. health care to be perceived as trustworthy and non-contradictory. Researchers and decision-makers should take notice of the beliefs and experiences among former smokers when designing health communication efforts. The effectiveness of health communication hinges on how it is taken up by its target group. Attending to the views of former smokers is thus a crucial step when designing health communication. Here, qualitative studies can play a crucial role as well, attending to potential intricacies that may be impossible to capture by survey research.

\section{References}

Bawden, D. and Robinson, L. (2009), "The dark side of information: overload, anxiety and other paradoxes and pathologies", Journal of Information Science, Vol. 35 No. 2, doi: 10.1177/ 0165551508095781 
Bawden, D. and Robinson, L. (2020), "Information overload: an overview", In: Oxford Encyclopedia of Political Decision Making, Oxford: Oxford University Press

Benigeri, M. and Pluye, P. (2003), "Shortcomings of health information on the internet", Health Promotion International, Vol. 18 No. 4, doi: 10.1093/heapro/dag409.

Bolin, K. and Lindgren, B. (2004), "Rökning - produktionsbortfall och sjukvårdskostnader", available at: www.who.int/fctc/reporting/Sweden_annex3_SmokingRelatedHealthCareCosts_2004.pdf (accessed 14 May 2020).

Carlsson, S., Andersson, T., Araghi, M., Galanti, R., Lager, A., Lundberg, M., Nilsson, P., Norberg, M., Pedersen, N.L., Trolle-Lagerros, Y. and Magnusson, C. (2017), "Smokeless tobacco (snus) is associated with an increased risk of type 2 diabetes: results from five pooled cohorts", JIM, doi: 10.1111/joim. 12592.

Carney, T., Myers, B.J., Louw, J. and Okwundu, C. (2016), "Brief school-based interventions and behavioural outcomes for substance-using adolescents”, doi: 10.1002/14651858.CD008969.pub3.

Clarke, E., Thompson, K., Weaver, S., Thompson, J. and ÓConnell, G. (2019), "Snus: a compelling harm reduction alternative to cigarettes", Harm Reduction Journal , Vol. 16 No. 1, doi: 10.1186/s12954-0190335-1.

Covello, V. and Sandman, P.M. (2001), "Risk communication: Evolution and revolution", in Wolbarst, A (Ed.), Solutions to an Environment in Peril, Johns Hopkins University Press (2001) pp.164-178, available at: http://202.29.106.169/views/conferences/apec/day2/risk_communication/reference_material/Annex \%202\%20to\%20Risk\%20Comm.pdf (accessed 29 June 2020).

Ekendahl, M. and Karlsson, P. (2015), "The credibility of risk information about licit substances: an exploratory study of attitudes among swedish adults", Nordic Studies on Alcohol and Drugs, Vol. 32 No. 4, doi: 10.1515\%2Fnsad-2015-0039.

European Commission (2008), "Scientific opinion on the health effects of smokeless tobacco products", available at: http://ec.europa.eu/health/ph_risk/committees/04_scenihr/docs/scenihr_o_013.pdf (accessed 20 May 2020).

Eurostat (2019), "Sustainable development in the European union", available at: https://ec.europa.eu/ eurostat/documents/3217494/9940483/KS-02-19-165-EN-N.pdf/1965d8f5-4532-49f9-98ca-5334b0652820 (accessed 4 June 2020).

Fischhoff, B., Bostrom, A. and Jacobs Quadrel, M. (1993), "Risk perception and communication", Annu. Rev. Publ. Health, doi: 10.1146/annurev.pu.14.050193.001151.

Food and Drug Administration (2019), "FDA grants first-ever modified risk orders to eight smokeless tobacco products", Newsletter, available at: www.fda.gov/news-events/press-announcements/fdagrants-first-ever-modified-risk-orders-eight-smokeless-tobacco-products (accessed 3 October 2020).

Hansson, J., Pedersen, N.L., Galanti, M.R., Andersson, T., Ahlbom, A., Hallqvist, J. and Magnusson, C. (2009), "Use of snus and risk for cardiovascular disease: results from the swedish twin registry", JIM, doi: 10.1111/j.1365-2796.2009.02081.x.

Haroon Ahmed, H., Naik, G., Willoughby, H. and Edwards, A.G.K. (2012), "Communicating risk", BMJ, Vol. 344 No. jun18 1, p. e3996, available at: www.bmj.com/content/344/bmj.e3996 (accessed 9 May 2020).

Hubbard, R., Lewis, S., Smith, C., Godfrey, C., Smeeth, L., Farrington, P. and Britton, J. (2005), "Use of nicotine replacement therapy and the risk of acute myocardial infarction, stroke, and death", Tobacco Control, Vol. 14 No. 6, doi: 10.1136/tc.2005.011387.

Johnson, D.J. (2014), "Controlling the flood: when more of a dose is less", Journal of Documentation, doi: 10.1108/JD-01-2013-0008.

Kaufman, A.R., Persoskie, A., Twesten, J., et al (2020), "A review of risk perception measurement in tobacco control research", Tobacco Control, doi: 10.1136/tobaccocontrol-2017-054005.

Kozlowski, L.T. and Sweanor, D. (2016), "Withholding differential risk information on legal consumer nicotine/tobacco products: the public health ethics of health information quarantines", International Journal of Drug Policy, Vol. 32, doi: 10.1016/j. drugpo.2016.03.014.

Levy, D.T., Mumford, E.A., Cumming, K.M., Gilpin, E.A., Giovino, G., Hyland, A., Sweanor, D. and Warner, K.E. (2004), "The relative risks of a low-nitrosamine smokeless tobacco product compared with smoking cigarettes: estimates of a panel of experts", Cancer Epidemiol Biomark and Prevention, Vol. 13 No. 12, pp. 2035-2042. 
Lund, K.E. and Vedoy, T.F. (2019), "Relative risk perceptions between snus and cigarettes in a SnusPrevalent society - an observational study over a 16 year period", International Journal of Environmental Research and Public Health, Vol. 16 No. 5, doi: 10.3390/ijerph16050879.

Luo, J., Ye, W., Zendehdel, K., Adami, J., Adami, H.-O., Boffetta, P. and Nyrén, O. (2007), "Oral use of Swedish moist snuff (snus) and risk for cancer of the mouth, lung, and pancreas in male construction workers: a retrospective cohort study", The Lancet, Vol. 369 No. 9578, pp. 2015-2020, doi: 10.1016/ S0140-6736(07)60678-3.

Nordenvall, C., Nilsson, P.J., Ye, W. and Nyrén, O. (2010), "Smoking, snus use and risk of right- and leftsided Colon, rectal and anal cancer: a 37-year follow-up study", IJC, doi: 10.1002/ijc.25305.

Nutt, D.J., Phillips, L.D., Balfour, D., Curran, H.V., Dockrell, M. and Foulds, J. (2014), "Estimating the harms of nicotine-containing products using the MCDA approach", Eur. Addict. Res, doi: 10.1159/ 000360220

Patwardhan, (2013), "Survey of GPs' understanding of tobacco and nicotine products", Drugs and Alcohol Today, doi: 10.1136/tobaccocontrol-2017-054005. S.R. and Murphy, M.A.

Psychologists Against Tobacco (2017), Snus som rökavvänjningsmetod [Snus as a smoking cessation aid], available at: http://www.psychologistsagainsttobacco.org/Default.aspx?PagelD= 18994966\&A=SearchResult\&SearchID=1417099\&ObjectID=18994966\&ObjectType=1 (accessed 15 May 2020).

Ramstedt, M., Lindell, A. and Raninen, J. (2013), "Tal om alkohol 2012. En statistisk årsrapport från Monitor-projektet” [Annual statistical report on alcohol]. Stockholm: SoRAD 2013. Research report no. 67.

Rayner, S. and Cantor, R. (1987), "How fair is safe enough? The cultural approach to societal technology choice", Risk Analysis, Vol. 7 No. 1, doi: 10.1111/j.1539-6924.1987.tb00963.x.

Rohrmann, B. and Renn, O. (2000), "Risk perception research", in Renn O., Rohrmann B. (Eds), CrossCultural Risk Perception. Technology, Risk, and Society (an International Series in Risk Analysis, Springer, Boston, MA, pp. 11-53, doi: 10.1007/978-1-4757-4891-8_1.

Sheeran, P., Harris, P.R. and Epton, T. (2014), "Does heightening risk appraisals change people's intentions and behavior? A Meta-analysis of experimental studies", Psychological Bulletin, Vol. 140 No. 2, pp. 511-543, doi: 10.1037/a0033065.

Shields, P.G. (2011), "Long-term nicotine replacement therapy: cancer risk in context", Cancer Prevention Research, Vol. 4 No. 11, doi: 10.1158/1940-6207.CAPR-11-0453.

Sjöberg, L., Moen, B.-E. and Rundmo, T. (2004), "Explaining risk perception. An evaluation of the psychometric paradigm in risk perception research", Trondheim: Rotunde. Rotunde, Vol. 84.

Sohlberg, T. (2014), Smoking Cessation in Sweden - Gender, Pathways and Identity, Diss, Stockholm: Stockholms Universitet.

Statistics Sweden (2020), "Statistics", available at: www.statistikdatabasen.scb.se/pxweb/sv/ssd/STAR T_LE_LE0101_LE0101H/LE01012019H06/table/tableViewLayout1/ (accessed 15 May 2020).

Swedish National Board of Health and Welfare (2014), "Registeruppgifter om tobaksrökningens skadeverkningar", available at: www.socialstyrelsen.se/globalassets/sharepoint-dokument/artikelkata log/statistik/2014-3-4.pdf (accessed 15 May 2020).

Swedish Quit-smoking-line (2019), "The truth about snus", available at: https://www.slutarokalinjen.se/ globalassets/verksamheter/sluta-roka-linjen/material/snusfoldern-ratt.pdf, (accessed 2 July 2020).

Wennberg, P., Svensson, J. and Ramstedt, M. (2011), "The effects of missing data when surveying alcohol habits", Nordic Studies on Alcohol and Drugs, Vol. 28 No. 1, doi: 10.2478/v10199-011-0004-5.

WHO (2020), "Health topic: tobacco", https://www.who.int/health-topics/tobacco\#tab=tab_1 (accessed 1 July 2020).

\section{Further reading}

Public Health Agency of Sweden (2018), available at: https://www.folkhalsomyndigheten.se/livsvillkorlevnadsvanor/alkohol-narkotika-dopning-tobak-och-spel-andts/tobak/utvecklingen-av-bruket/bruk-avcigaretter-snus-och-e-cigaretter-i-den-vuxna-befolkningen/ (accessed 29 June 2020). 
von Wagner, C., Knight, K., Steptoe, A. and Wardle, J. (2007), "Functional health literacy and healthpromoting behavior in a national sample of British adults", Journal of Epidemiology \& Community Health, Vol. 61 No. 12, doi: 10.1136/jech.2006.053967.

WHO Framework Convention on Tobacco Control (2005), https://apps.who.int/iris/bitstream/handle/ 10665/42811/9241591013. pdf; jsessionid=D0656BF1A5936872ABF86FE39CDB50D7? sequence=1 (accessed 28 September 2020).

\section{Corresponding author}

Tove Sohlberg can be contacted at: tove.sohlberg@sociology.su.se

For instructions on how to order reprints of this article, please visit our website: www.emeraldgrouppublishing.com/licensing/reprints.htm

Or contact us for further details: permissions@emeraldinsight.com 